\title{
SUGGESTED COMPETENCES FOR A PRECEPTOR TRAINING PROGRAMME
}

\author{
Botma Yvonne
}

\begin{abstract}
Purpose: Facilitating learning in the clinical context is a complex act for which preceptors should be trained. However, there is no consensus on what should be included in a training programme for preceptors. The purpose of the article is to describe the competences of a preceptor that emanated from a consensus reaching process among nurse educators in South Africa.

Methodology: Nurse educators reached consensus on the core competences of a preceptor through nominal groups. Non-probability convenient sampling was used to sample nurse educators from universities as well as public and private nursing colleges. The two nominal groups generated data that were combined to identify the content of preceptor training programme.

Results: Key findings were that preceptors should be able to facilitate learning through a variety of techniques and perform valid and reliable assessment. Preceptors should support students in finding and implementing best available evidence of care for a specific patient.

Conclusion and recommendation: It is the responsibility of nursing education institutions to produce clinically competent nurses. A competent nurse is able to think critically, reason clinically, make sound clinical judgments, and reflect on the thinking processes applied. Preceptors, therefore, should support nursing students in these thinking processes and create opportunities where they can practice under supervision to become competent nurses. The training programme should enable preceptors to facilitating learning in the clinical environment through a variety of techniques, conduct valid and reliable assessments, and support students in implementing best practice guidelines.
\end{abstract}

Keywords: preceptor, competence, training programme

\section{Introduction}

The nursing summit of 2011 held in Gauteng, resulted in a nursing compact in which the nurse educators of South Africa reiterated their commitment to produce clinically competent nurses (Nursing Summit Organising Committee and the Ministerial Task Team, 2012). This commitment is feasible because in addition to a full 480-credit,four-year programme, all student nurses must comply with the South African Nursing Council (SANC) requirement of 4000 clinical hours over the four-year training period. According to the Nursing Education Stakeholders (NES) group (Nursing Education Stakeholders [NES], 2012, p. 50), competence in nursing is based on -

"... the ability to integrate knowledge from all disciplines in order to identify the problem, understand the theory related to the problem, as well as the appropriate response, treatment, and care of the patient. All this integrated knowledge should then be applied in a practical event or situation in a real-life setting or simulation".

Besides being able to integrate knowledge and to apply it in specific contexts, Banning (2008) states that competent nurses "think about thinking", thereby creating meta-cognitive knowledge through the reflective process. Figure 1 illustrates the equivalence between the knowledge domains and thinking processes with an example of application. These thinking processes are not unique to nursing students; they are applicable to all students in health sciences. 


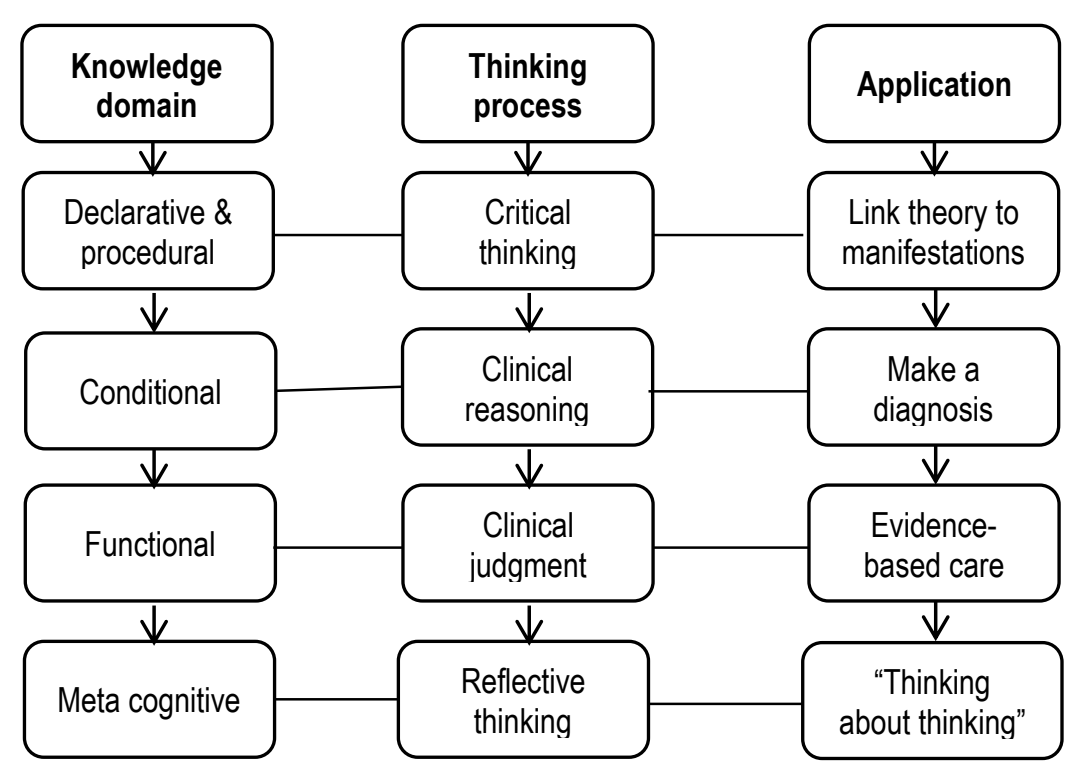

Figure 1: Diagram depicting knowledge domains with corresponding thinking processes.

An analysis of the definition of competence (NES, 2012) indicates that foundational knowledge from all disciplines is used during critical thinking processes to demonstrate understanding and insight into the related theories (see Figure 1)(Biggs \& Tang, 2011). A competent student is expected to be able to explain the manifestations and predict the progression of a condition (Tanner, 2006). Reasoning about the possible interventions remains a pure cognitive exercise and it is equated to critical thinking (Chang, Chang, Kuo, Yang, \& Chou, 2011). According to this analysis, the student would be able to explain why a patient, who had a severe myocardial infarction, may present with oedema.

Clinical reasoning processes are demonstrated when the student uses conditional knowledge or patient-specific information. An example of this type of clinical reasoning may be that the student states that the patient has heart failure due to myocardial muscle failure as confirmed by low ventricular ejection fraction and high afterload (vascular resistance). Reasoning is not only related to a theoretical case, but to a real-life situation (Chang et al., 2011). Making a diagnosis reflects clinical reasoning because it involves an inferential process of collecting and evaluating data (Banning, 2008).

The critical thinking and clinical reasoning processes culminate in clinical judgment, which is demonstrated when the decision is made on the treatment options that will be the most beneficial to the patient (Chang et al., 2011; Tanner, 2006). At this stage, the student demonstrates functional knowledge.

Meta-cognitive knowledge is developed when the student critically reflects on and learns from the situation (Bruce, Klopper, \& Mellish, 2011). Figure 1 presents a schematic diagram of the knowledge domains and thinking processes as discussed. The word "competence" or "competent" is often used in health professions programmes but the depth and the complexity of the concept are rarely fully comprehended.

In order to give effect to the resolutions of the 2011 nursing compact, the Minister of Health created the nursing ministerial task team. One of the seven strategic priorities identified by the task team was to address education and training of nurses with a specific recommendation to initiate the Model for Clinical Education and Training (Nursing Summit Organising Committee and the Ministerial Task Team, 
2012). Preceptors facilitate student learning during work-integrated learning experiences and are the link between the Nursing Education Institution (NEI) and clinical practice. The preceptor is the lynchpin of the NEI, clinical practice, and student triad (Botma, Hurter, \& Kotze, 2012; Burns \& Northcutt, 2009; Smedley \& Penny, 2009) and therefore provides system support. Lack of precepting experience reduces the level and type of support offered by preceptors (Williamson, Callaghan, Whittlesea, \& Heath, 2011). Preceptors provide tangible support by showing students how to engage in activities and do relevant procedures (Smedley \& Penny, 2009), give cognitive support by facilitating reasoning processes, and provide emotional support when they establish a trust relationship with students, encouraging them to reflect on and learn from their clinical experiences (Brathwaite \& Lemonde, 2011; Williamson, Callaghan, Whittlesea, \& Heath, 2011).

Through deductive reasoning, it is evident that the purpose of the preceptor is to assist the student in becoming competent, in other words to facilitate the processes of critical thinking, clinical reasoning, clinical judgment and reflection. An untrained and incompetent preceptor may not be able to support students in becoming competent in the reasoning processes (Williamson, Callaghan, Whittlesea, \& Heath, 2011) and ultimately in the rendering of quality healthcare. Facilitating learning in the clinical setting is a complex act that requires integration of many skills (Liu, Lei, Mingxia, \& Haobin, 2010). Hence, preceptor development and training should meet the diverse needs of all preceptors by providing a constellation of educational activities and support measures (Vos \& Trewet, 2012). There is consensus in the literature on preceptors that they should be trained prior to precepting students, and training programmes should support professional development (Boyle, Morgan, Layson-Wolf, \& De Bittner, 2009; Duffy, 2009; Vos \& Trewet, 2012).

Formal training of preceptors is mostly non-existent and the training that occurs is haphazardly done (Larsen \& Zahner, 2011; Mulder \& Uys, 2012; Troxel, 2009; Zilembo \& Monterosso, 2008). It is also evident that a good clinician is not necessarily a good preceptor (Ortman, Mann, \& Arsenault, 2010; Troxel, 2009). Bott and Lawlor (2011) support Liu et al. (2010) in their viewpoint that preceptors are the key providers of individualised experiential learning opportunities and that clinical training should move away from the emphasis on assessment to one of support and learning. This viewpoint is aligned with Davidson's (2009) statement that to execute a task is a learning objective that does not promote or test the ability to analyse, solve problems, or create care plans based on the patients' unique problems and thus do not meet the commitment to deliver competent nurses. Ness, Duffy, McCallum, and Price (2010) have a similar view, stating that decision-making is central to effective clinical practice and that preceptors should assist students to benefit optimally from the clinical learning experience.

There is an abundance of literature on training programmes for preceptors; the issue is the little consensus that exists on what should be included in such a training programme. Workshops and workbooks that are offered face-to-face are the most common mode of offering training programmes (Larsen \& Zahner, 2011; Vos \& Trewet, 2012), but online programmes are becoming more popular as they accommodate preceptors in almost any location (Burns \& Northcutt, 2009; Conway-Klaassen, Brennecke, Wiesner, \& Spannaus-Martin, 2012; Larsen \& Zahner, 2011; Stodel, Montpetit, Eyre, Prentice, \& Johnston, 2012). An interesting approach is the use of hard copy case studies that pharmacology students complete in the clinical setting with the guidance of preceptors (Karimi, Cawley, \& Arendt, 2011).

The author conducted a scoping analysis of the content of ten nurse preceptor training programmes found in the literature. From a list of 36 topics, only five (14\%) were included in $50 \%$ of the programmes. Although this was by no means an exhaustive analysis of all available existing training programmes the list was found to be inadequate in terms of the wide variety of topics addressed in the training programmes. This variation may also be the reason why Udlis (2008) concluded in an integrative review that "... preceptorship failed to demonstrate significant benefits over traditional clinical placements in the areas of critical thinking and clinical competence ...". Listed below are all the 
topics that were included in at least half of the programmes reviewed. The numbers in brackets indicate the number of programmes that address the topic.

- Clinical teaching strategies (9)

- Role and responsibilities of the preceptor (7)

- Giving feedback (5)

- Adult learning theories (5)

- Assessment of students (5)

The lack of consensus in the literature on topics of a training programme for preceptors highlights the need to determine the core competences of a preceptor who will be able to assist students to become competent practitioners. The purpose of the article is to describe the competences of a preceptor that emanated from a consensus reaching process among nurse educators in South Africa.

\section{Research design and methods}

The researcher used the nominal group technique to explore and describe the core competences of nurse preceptors in South Africa; hence, the study meets the criteria of an explorative descriptive study design. The nominal group technique is a once-off consensus seeking data gathering method that is ideal to make decisions and solve problems (Abdullah \& Islam, 2011).

\section{Population and sample}

The population comprised all nurse educators in South Africa, approximately 12400 (SANC, 2012). Non-probability convenient sampling was used for two nominal groups as the nurse educators attending specific events were asked to participate in the nominal group. The first nominal group was conducted in 2013 at a meeting of the Forum of University Nursing Deans in South Africa (FUNDISA) at which 33 participants represented the 22 universities that offer degree nursing programmes. It was convenient to use the opportunity during a FUNDISA meeting because most of the universities were represented and it would have been almost impossible to get representatives of all the universities together for the study when using this technique.

The second nominal group was conducted during a workshop offered at the Annual Nurse Educators Conference (ANEC) in 2013. The researcher planned to accommodate 30 participants in the workshop but as over 100 conference delegates registered for the workshop, the nominal group technique had to be adapted. The adaptation is described in more detail under the section dealing with data collection process and analysis. In this group participants represented universities as well as public and private nursing colleges from various provinces in the country. No biographical data of the participants were gathered due to the large number of participants.

\section{Data gathering method}

A nominal group technique is a consensus-seeking method through a structured face-to-face interview group session that is moderated by a facilitator (Varga-Atkins, 2011). All participants have an equal voice through the silent generation of ideas and listing of all the responses from every participant during the round-robin phase. Participants rank ideas through an anonymous voting process. One of the biggest advantages of the nominal group technique is that the results are available immediately and the participants feel part of the decision-making process (Abdullah \& Islam, 2011; Delbecq, Van de Ven \& Gustafson, 1975; Varga-Atkins, 2011) - therefore "buy-in" from the participants is promoted. It is an effective technique when decisions need to be made and a single topic, for example the core competences of a preceptor, is explored. It is also very useful when various stakeholder groups, e.g. nursing education institutions related to universities as well as public and private nursing colleges are 
consulted sometimes simultaneously (Abdullah \& Islam, 2011; Varga-Atkins, 2011) because the technique is structured and all stakeholders have an equal voice during the process.

\section{Data collection process and analysis}

At the beginning of each nominal group session, the author explained the purpose of attaining consensus on the core competences of a preceptor in nursing by reminding them of the commitment made by nurse educators during the nursing summit of 2011 to deliver competent nurse practitioners. In order to establish a common understanding the author displayed the definition of competence as defined by the Nurse Education Stakeholders (2012) on a PowerPoint slide. The author, also the moderator of both sessions, explained to the audience the formal steps of a nominal group and that the data are for research purposes. The moderator (author) assured the prospective participants that participation was voluntary and those who did not want to participate were free to leave the venue before commencement of the nominal group or at any time during the process. She also informed participants that the proposal had received ethical approval and clearance from the Ethics Committee of the Faculty of Health Sciences at the university with which the author was affiliated (ECUFS NR 134/2013).

Although both groups were bigger than the recommended number of participants, the nominal group process was conducted according to a systematic approach as described by Abdullah and Islam (2011). The nominal group process did not deviate from the procedure followed with the FUNDISA group. The unexpectedly large number of about 100 participants at the Annual Nurse Educators Conference (ANEC) required that the moderator adapt the nominal group technique or steps while keeping to the sequence and principles of the process. Participants were asked to write down ideas in their notebooks on what a preceptor should be able to do (behavioural outcomes) to assist nursing students in becoming competent. The moderator then asked participants to voice their suggestions, and these were written on a flip chart. Not everybody had the opportunity to mention his/her idea due to the large number of participants. This process continued until no new ideas were forthcoming. The author read each statement from the flip chart and asked the participants to clarify any aspects that needed clarification to reach an agreement on the meaning of the statement. During this step of clarification, the participants spontaneously started to group similar ideas and to reject some ideas as they related to pre-requisites for the appointment of preceptors. On completion of this step, a greatly reduced number of ideas remained on the flip chart. In order to accomplish the voting step, each participant was asked to prioritise the five most important ideas with five being the most important and one the least important. They then formed small groups of five to seven people per group to determine the top five priorities per group by calculating the sum of the values given per idea. The idea with the highest group score was allocated a five and so forth. The groups' values were captured on an Excel spreadsheet that was projected onto a big screen. As the process progressed the participants tracked the generation of data, corrected incorrect capturing, and witnessed priorities emerging from the data generated.

\section{Findings}

Although the two groups generated related ideas, the totals differed. Figure 1 depicts the ideas generated by the two groups as well as the weight allocated by the two groups to each point. Zero weight per idea indicates that the group did not raise the idea. The author added the scores per idea in order to calculate the priorities of the combined data.

With the highest sum of 234, it was clear that the most important competence as identified by the participants was that of preceptors being able to facilitate learning by using a variety of coaching, mentoring and facilitation techniques. Although the sum of 118 indicated that the second most important competence was the ability to identify the learning needs of nursing students, the FUNDISA group did not rate this as important. Both groups identified assessment skills as an important idea 
with a sum of 92. Only the FUNDISA group identified the development of clinical judgment as important. Even without a single vote from the ANEC group, clinical judgement remained a priority. Both groups indicated that the ability to promote implementation of best practice guidelines was an important competence that the preceptors must have. Although the FUNDISA group identified communication skills as a competence, the ANEC group decided that it should be a pre-requisite for preceptors.

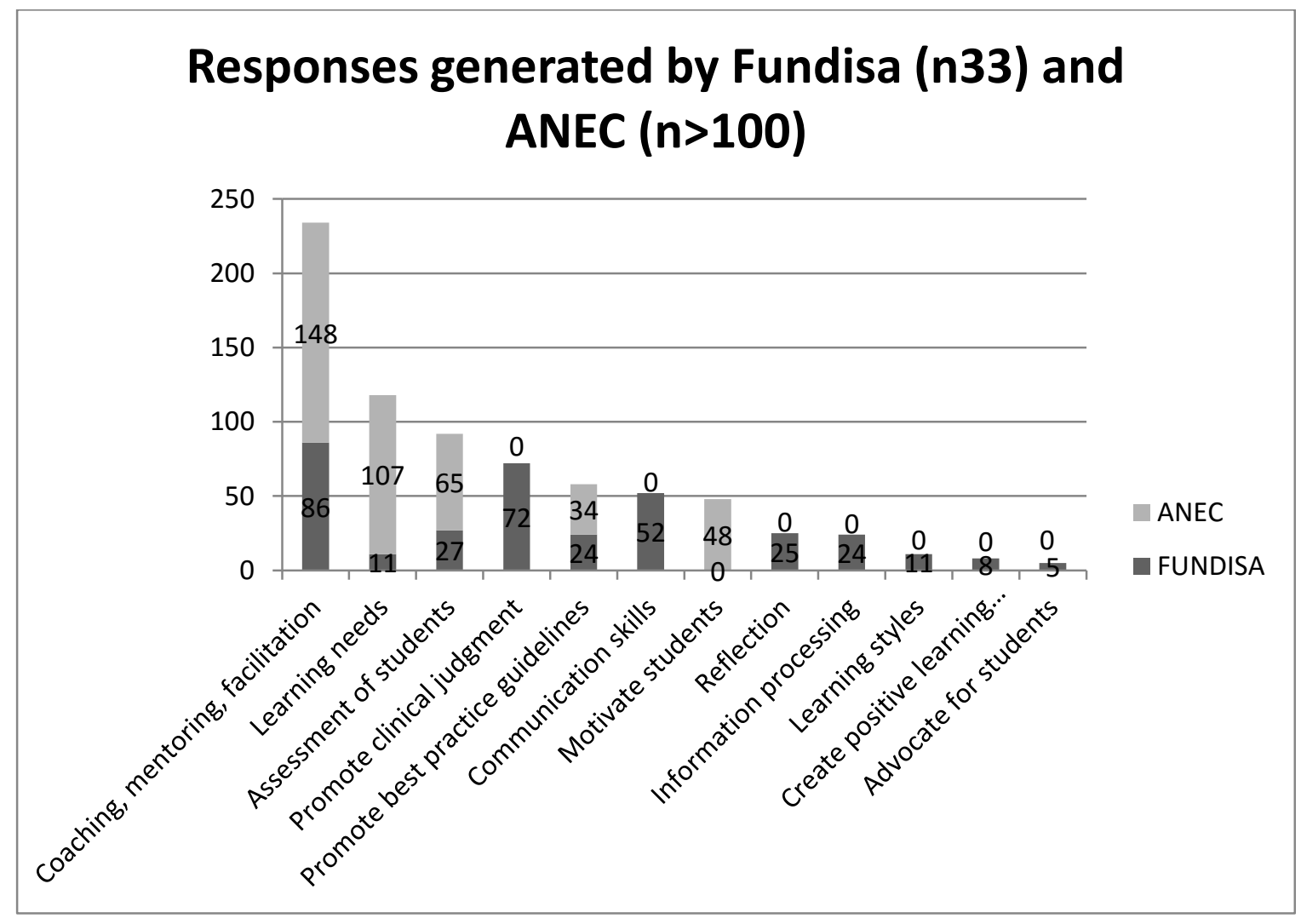

Figure 1: Responses per item

Although it was not the purpose of the research to determine prerequisites for the appointment of a preceptor, the second nominal group generated ideas on the topic. These ideas were initially listed as competences but during step two of the process, the group clustered them as prerequisites. It should be noted that the list of prerequisites in Table 1 is by no means exhaustive according to the literature, but the table encompasses all the ideas generated by the participants. Supporting authors are indicated as citations in the right-hand column.

Table 1: Prerequisites for the appointment of a preceptors

\begin{tabular}{|l|l|}
\hline Prerequisite & Supporting authors \\
\hline $\begin{array}{l}\text { A preceptor should: } \\
\text { be a competent/expert practitioner }\end{array}$ & (Burns, Beauchesne, Ryan-Krause, \& Sawin, 2000; \\
& $\begin{array}{l}\text { Dube \& Jooste, 2006; Giallonardo, Wong, \& } \\
\text { Iwasiw, 2010; Huybrecht, Loeckx, Quaeyhaegens, } \\
\text { De Tobel, \& Mistiaen, 2011; James \& Chapman, } \\
\text { 2010; Zilembo \& Monterosso, 2008) }\end{array}$ \\
\end{tabular}




\begin{tabular}{|l|l|}
\hline Prerequisite & Supporting authors \\
\hline 2. $\begin{array}{l}\text { be a good communicator/listener } \\
\text { 3. } \begin{array}{l}\text { respect students } \\
\text { James \& Chapman, 2010; Omansky, 2010; Ortman } \\
\text { et al., 2010) }\end{array} \\
\text { (James \& Chapman, 2010; Myrick \& Yonge, 2002; } \\
\text { Smedley \& Penny, 2009) } \\
\text { be a caring and compassionate person } \\
\text { (Haggerty, Holloway, \& Wilson, 2012; Zilembo \& } \\
\begin{array}{l}\text { Monterosso, 2008) } \\
\text { be a role-model (exhibit professional and behaviour) }\end{array}\end{array}$ \\
$\begin{array}{l}\text { (Omer, Suliman, Thomas, \& Joseph, 2013; Zilembo } \\
\text { \& Monterosso, 2008) }\end{array}$ \\
\hline
\end{tabular}

\section{Discussion}

Clinical teaching skill is a topic that appears in most (90\%) of the preceptor training programmes. According to Conway-Klaassen et al. (2012), preceptors should focus on supporting nursing students to apply what they have learned in the theory classes. This viewpoint supports the stance by González, Palencia, Umaña, Galindo, and Villafrade (2008) that the real-life situation is only an excuse to involve the preceptor with the nursing student's thinking process in order to promote meaningful learning. Promoting critical thinking and clinical reasoning is the core business of the preceptor. It is of interest that the Nursing Education Stakeholders (NES, 2012) motivated that the clinical reasoning ability of the preceptor candidate should be the deciding factor for appointment. The preceptor should be able to function at a high cognitive level and apply higher-order thinking processes. Larsen and Zahner (2011) have reported that preceptors with higher levels of education demonstrated higher selfefficacy scores.

Techniques to enhance facilitation skills of preceptors may include, but are not limited to, questioning (Ness et al., 2010), guided reflection (Forneris \& Peden-McAlpine, 2006; Wade \& Hayes, 2010), briefing and de-briefing (Ness et al., 2010), thinking aloud (Carlson, Wann-Hansson, \& Pilhammer, 2009), providing constructive feedback (Clynes \& Raftery, 2008; Huybrecht et al., 2011; Wade \& Hayes, 2010), talking through (Chen, Duh, Feng, \& Huang, 2011), clinical conferences (Wade \& Hayes, 2010), case presentations (Myrick \& Yonge, 2002), modelling (Lundberg, 2008), and five-minute preceptor technique (Bott \& Lawlor, 2011; Gallagher, Tweed, Hanna, Winter, \& Hoare, 2012). Results from this study support Carlson's (2013) recommendations that preceptor preparation programmes should focus on reflection, critical thinking and communication skills because precepting is a complex and advanced nursing competence for which preceptors should be properly prepared.

Identification of learning needs is inclusive of many of the abovementioned clinical teaching techniques, for example, Ness et al. (2010) argued that during debriefing of the nursing student, the preceptor should assess whether the learning needs were addressed and identify new learning needs. Bott and Lawlor (2011) described how, during the five-minute preceptor technique, the nursing student is given the opportunity to demonstrate related knowledge and skills in order to confirm or refute the initial judgment on learning needs. Identification of learning needs is also inherent in effective reflective practice.

Coaching, mentoring and facilitation techniques received the highest score in this study. The preceptor should be able to facilitate higher-order thinking processes through a variety of techniques in order to support the student in making sound clinical judgments and developing meta-cognitive knowledge. 
Although some authors have appealed for clinical training to move away from emphasis on assessment to one of learning (Conway-Klaassen et al., 2012; Liu et al., 2010), assessment as a competence cannot be completely excluded. Preceptorship is normally not associated with assessment of nursing students because assessment undermines relationships (Bray \& Nettleton, 2007), but due to increased student intake numbers, academic staff can no longer assess all students. Therefore it is imperative that preceptors should be familiar with the assessment tools and be taught the principles of valid and reliable assessment (Andrews et al., 2010; Bray \& Nettleton, 2007). Every assessment should become a learning experience through the provision of constructive feedback (Huybrecht et al., 2011; Smedley \& Penny, 2009). A preceptor should be able to conduct valid and reliable assessment of students in order to improve their performance.

A significant finding in this study is that the preceptor should be able to support the nursing student in finding and implementing best practice guidelines to render the best possible care. In order to dispel the misconception that an article or policy equates best practice guideline, preceptors should understand the process of developing best practice guidelines. Theory educators, preceptors and nurse clinicians should collaborate to ensure uniformity in the best practice guidelines recommended to the students. Preceptors should be confident in searching for the best practice guidelines; otherwise they will be unable to support students in their efforts to implement evidence-based practice. No literature was found on clinical training and precepting that supports the proposition that preceptors should promote the implementation of evidence-based practice. It is logical that preceptors should be able to facilitate the implementation of best practice guidelines, because the ability to make sound clinical judgments include deciding on the best treatment for the patient, which should be informed by the best available evidence. Therefore, preceptors must be able to support students in incorporating best available evidence into the care plan of a patient.

\section{Conclusion}

There is wide disparity in the literature on which content should be included in a training programme for preceptors. The author tried to reach consensus among nurse educators in South Africa on what the competences should be. Three core competences for preceptors were formulated based on the findings of two nominal groups in which representatives from the university, public and private nursing education institutions participated. The three competences were that the preceptor should be able to:

1. facilitate higher-order thinking processes through a variety of techniques in order to support the student in making sound clinical judgments and developing meta-cognitive knowledge;

2. conduct valid and reliable assessment of students in order to improve performance; and

3. support students in incorporating best available evidence into the care plan of a patient.

The three above-mentioned competences confirm that preceptors should focus on the learning process and not on tasks. These competences are usually not included in the preregistration programme; therefore training of preceptors to become competent in those required areas are of paramount importance. It is also clear that an excellent nurse clinician may not necessarily be an excellent preceptor without the enabling training.

A limitation of the research was that the author had to adjust the steps in the nominal group technique to accommodate the large groups. During the second nominal group at ANEC, not everybody had an equal voice due to the size of the group. Bias may have been introduced because the ideas which were listed belonged to those who were willing to speak up in the group. Despite the adjustment in the steps, the author adhered to the sequence and the principles of the research technique. A number of smaller nominal groups would have been better than the single large group of above 100; but the 
ANEC offered a once-off opportunity, since the researcher did not have the resources to travel to all the nursing education institutions represented at the workshop.

The findings described in this article may serve as the basis for a national or international survey on what the competences of a preceptor in nursing should be. Further research should be conducted to explore the views of preceptors on promoting implementation of evidence-based practice.

Another recommendation is that the stated competences should be constructively aligned with the assessment of the preceptors and the teaching and learning techniques used in offering the training programme. In aligning the assessment of the preceptors, the trainer should ask the following questions, namely "What will be the evidence that the preceptor require to facilitate higher-order thinking ... or conduct valid and reliable assessment ... or support students in finding the best available evidence ...?" and "what content and skills do preceptors need to produce the evidence required in clinical training?" (Botma, Brysiewicz, Chipps, Mthembu, \& Phillips, 2013).

\section{Acknowledgements}

The author acknowledges all the participants who willingly contributed to the discussions and the CEO of FUNDISA who gave her the opportunity to gather data during a formal meeting as well as the organising committee of the ANEC for allocating her a slot to gather data. The contributions of the critical reader, Dr Ruth Albertyn, and of the language editor, Ms Jackie Viljoen, served to enhance the readability of the article. Their contributions are much appreciated.

\section{References}

Abdullah, M. M. B., \& Islam, R. (2011). Nominal Group Technique and its Applications in Managing Quality in Higher Education. Pakistan Journal of Commerce and Social Science, 5(1), 81-99.

Andrews, M., Brewer, M., Buchan, T., Denne, A., Hammond, J., \& Hardy, G. (2010). Implementation and sustainability of the nursing and midwifery standards for mentoring in the UK. Nurse Education in Practice, 10(2010), 251-255.

Banning, M. (2008). The think aloud approach as an educational tool to develop and assess clinical reasoning in undergraduate students. Nurse Education Today, 28, 8-14.

Botma, Y., Brysiewicz, P., Chipps, J., Mthembu, S. \& Phillips, M. 2013. Creating stimulating learning opportunities. Cape Town: Pearson Education South Africa.

Botma, Y., Hurter, S., \& Kotze, R. (2012). Responsibilities of nursing schools with regard to peer mentoring Nurse Education Today . 33(8): 808-813.

Bott, G., \& Lawlor, Y. (2011). A clinical teaching technique for nurse preceptors: the five minute preceptor. Journal of Professional Nursing, 27(1): 35-42.

Boyle, C. J., Morgan, J. A., Layson-wolf, C., \& de Bittner, M. R. (2009). Developing and Implementing an Academy of Preceptors. American Journal of Pharmaceutical Education, 73(2), Article 34.

Bray, L., \& Nettleton, P. (2007). Assessor or mentor? Role confusion in professional education. Nurse education today, $27(8), 848-855$.

Bruce, J., Klopper, H., \& Mellish, J. (2011). Teaching and learning the practice of nursing (5th ed.). Cape Town: Pearson Education. 
Burns, C., Beauchesne, M., Ryan-Krause, P., \& Sawin, K. (2000). Mastering the preceptor role: challenges of clinical teaching. Journal of Pediatric Health Care, 20(3), 172-83. doi:10.1016/j.pedhc.2005.10.012

Burns, H. K., \& Northcutt, T. (2009a). Supporting preceptors: a three-pronged approach for success. Journal of continuing education in nursing, 40(11), 509-13.

Carlson, E. (2013). Precepting and symbolic interactionism--a theoretical look at preceptorship during clinical practice. Journal of Advanced Nursing, 69(2), 457-64.

Chang, M. J., Chang, Y.-J., Kuo, S.-H., Yang, Y.-H., \& Chou, F.-H. (2011). Relationships between critical thinking ability and nursing competence in clinical nurses. Journal of Clinical Nursing, 20(21-22), 322432.

Chen, Y., Duh, Y., Feng, Y., \& Huang, Y. (2011). Preceptors ' Experiences Training New Graduate Nurses: A Hermeneutic Phenomenological Approach. Journal of Nursing Research, 19(2), 132-139.

Clynes, M. P., \& Raftery, S. E. C. (2008). Feedback: an essential element of student learning in clinical practice. Nurse education in practice, $8(6), 405-411$.

Conway-Klaassen, J. M., Brennecke, P. J., Wiesner, S. M., \& Spannaus-Martin, D. J. (2012). Development of online conferencing and web-based in-service modules for preceptor training. Clinical laboratory science : Journal of the American Society for Medical Technology, 25(4), 26-33.

Davidson, J. E. (2009). Preceptor Use of Classroom Assessment Techniques to Stimulate Higher-Order Thinking in the Clinical Setting. Journal of Continuing Education in Nursing, 40(3), 139-144.

Delbecq, A. L., \& Van De Ven, A H Gustafson, D. H. (1975). Group techniques for program planning - a guide to nominal group and Delphi processes. Glenview: Scott Foresman and Company.

Dube, A., \& Jooste, K. (2006). The leadership characteristics of the preceptor in selected clinical practice settings in Botswana. Curationis, 29(3), 24-40.

Duffy, A. (2009). Guiding students through reflective practice - The preceptors' experiences. A qualitative descriptive study. Nurse Education in Practice, 9(3), 166-175.

Forneris, S. G., \& Peden-McAlpine, C. J. (2006). International Journal of Nursing Contextual Learning : A Reflective Learning Intervention for Nursing Education Contextual Learning : A Reflective Learning Intervention for Nursing Education $*, 3(1)$.

Gallagher, P., Tweed, M., Hanna, S., Winter, H., \& Hoare, K. (2012). Developing the One-Minute Preceptor. The Clinical Teacher, 9, 358-362.

Giallonardo, L. M., Wong, C. A, \& Iwasiw, C. L. (2010). Authentic leadership of preceptors: predictor of new graduate nurses' work engagement and job satisfaction. Journal of Nursing Management, 18(8), 993-1003.

González, H. L., Palencia, A. P., Umaña, L. A., Galindo, L., \& Villafrade M, L. A. (2008). Mediated learning experience and concept maps: a pedagogical tool for achieving meaningful learning in medical physiology students. Advances in Physiology Education, 32(4), 312-6.

Haggerty, C., Holloway, K., \& Wilson, D. (2012). Entry to nursing practice preceptor education and support: could we do it better? Nursing Praxis in New Zealand, 28(1), 30-39. 
Huybrecht, S., Loeckx, W., Quaeyhaegens, Y., De Tobel, D., \& Mistiaen, W. (2011). Mentoring in nursing education: perceived characteristics of mentors and the consequences of mentorship. Nurse Education Today, 31(3), 274-278.

James, A., \& Chapman, Y. (2010). Preceptors and patients - the power of two: nursing student experiences on their first acute clinical placement. Contemporary Nurse, 34(1), 34-47.

Karimi, R., Cawley, P., \& Arendt, C. S. (2011). Learning bridge tool to improve student learning, preceptor training, and faculty teamwork. American Journal of Pharmaceutical Education, 75(3), Article 46.

Larsen, R., \& Zahner, S. J. (2011). The impact of Web-delivered education on preceptor role selfefficacy and knowledge in public health nurses. Public Health Nursing (Boston, Mass.), 28(4), 349-356.

Liu, M., Lei, Y., Mingxia, Z., \& Haobin, Y. (2010). Lived experiences of clinical preceptors: a phenomenological study. Nurse education today, 30(8), 804-808.

Lundberg, K. M. (2008). Promoting self-confidence in clinical nursing students. Nurse educator, 33(2), 86-89.

Melnyk, B. M., Fineout-Overholt, E., \& Williamson, K. W. (2010). The Seven Steps of Evidence-Based Practice. American Journal of Nursing, 110(1), 51-53.

Mulder, M., \& Uys, L. R. (2012). Baseline measurement of the implementation process of the proposed model for clinical nursing education and training in South African universities. In L. R. Uys \& H. C. Klopper (Eds.), Trends in Nursing 2012 (pp. 59-84). Pretoria: FUNDISA.

Myrick, F., \& Yonge, O. (2002). Preceptor questioning and student critical thinking. Journal of Professional Nursing, 18(3), 176-181.

Ness, V., Duffy, K., McCallum, J., \& Price, L. (2010). Supporting and mentoring nursing students in practice. Nursing standard (Royal College of Nursing (Great Britain) : 1987), 25(1), 41-6.

Nursing Education Stakeholders (NES). (2012). A proposed model for clinical nursing education and training in South Africa. In Trends in Nursing 2012 (pp. 49-58). Pretoria: FUNDISA.

Nursing Summit Organising Committee and the Ministerial Task Team. (2012). The nursing summit of 2011. In Trends in Nursing 2012 (pp. 33-48). Pretoria: FUNDISA.

Omansky, G. L. (2010). Staff nurses' experiences as preceptors and mentors: an integrative review. Journal of nursing management, 18(6), 697-703.

Omer, T. Y., Suliman, W. a, Thomas, L., \& Joseph, J. (2013). Perception of nursing students to two models of preceptorship in clinical training. Nurse Education in Practice, 13(3), 155-160.

Ortman, D., Mann, L., \& Arsenault, J. F. (2010). Perceived Roles, Benefits, and Supports for Dietetic Internship Preceptors. Canadian Journal of Dietetic Practice and Research, 71(1), 33-38.

Smedley, A., \& Penny, D. (2009). A Partnership Approach to the Preparation of Preceptors. Nursing Education Perspectives, 30(1), 31-36.

South African Nursing Council (SANC). 2012. Additional qualifications on the register of nurses and midwives. Online. Available from: www.sanc.co.za/stats [2013/12/11].

South African Nursing Council (SANC). n.d. Nursing Education and Training Standards. Online. Available from: www.sanc.co.za [2013/12/11]. 
Stodel, E. J., Montpetit, M., Eyre, A., Prentice, M., \& Johnston, M. (2012). The Academic Support Process (ASP) website: helping preceptors develop resident learning plans and track progress. Medical teacher, 34(5), e300-308. doi:10.3109/0142159X.2012.670328

Tanner, C. A. (2006). Thinking like a nurse: a research-based model of clinical judgment in nursing. The Journal of nursing education, 45(6), 204-11.

Troxel, D. (2009). Connections: Online preceptor education. Nursing Management, (October), 32-37.

Udlis, K. A. (2008). Preceptorship in undergraduate nursing education: an integrative review. The Journal of Nursing Education, 47(1), 20-9.

Varga-Atkins, T. (2011). The Nominal Group Technique - a practical guide for facilitators. Liverpool.

Vos, S. S., \& Trewet, C. B. (2012). Experiential Education a comprehensive approach to preceptor development. American Journal of Pharmaceutical Education, 76(3), Article 47.

Wade, G. H., \& Hayes, E. (2010). Challenges and opportunities associated with preceptored community health clinical experiences. Public Health Nursing (Boston, Mass.), 27(5), 459-467.

Zilembo, M., \& Monterosso, L. (2008). Nursing students perceptions of desirable leadership qualities in nurse preceptors: a descriptive survey. Contemporary Nurse, 27(2), 194-206. 